\title{
Comparison of central corneal thickness measurements obtained by community optometrists to those obtained in secondary care
}

\author{
Laura Hughes ${ }^{1} \cdot$ Cheng Yi Loo ${ }^{2} \cdot$ Brian Hogan $\mathbb{D}^{2} \cdot$ Huai Ling $\operatorname{Tan}^{2} \cdot$ Ling Shan Tang ${ }^{2} \cdot$ Andrew J Tatham ${ }^{1}$
}

Received: 25 August 2017 / Revised: 26 April 2018 / Accepted: 3 May 2018 / Published online: 23 July 2018

(C) The Royal College of Ophthalmologists 2018

\begin{abstract}
Purpose Corneal central thickness (CCT) is an important risk factor for glaucoma, which also influences intraocular pressure (IOP) measurements. Recently, all community optometrists in Scotland were provided with pachymeters. This study examined the accuracy of CCT measured by community optometrists compared to measurements in the glaucoma clinic. Methods A retrospective analysis of consecutive patients referred to the glaucoma clinic at a university hospital between June and November 2016. 142 of 715 (19.9\%) patients had CCT measurements included in the referral, all of whom had repeat measurements in the glaucoma clinic. CCT was measured using the PachPen (Accutome Inc) which generates a CCT reading by automatically taking the average of up to 9 measurements. Measurements were compared using Bland-Altman analysis.

Results CCT measured by community optometrists was slightly thicker than CCT in the glaucoma clinic $(558.3 \pm 41.5$ vs. $552.6 \pm 58.8 \mu \mathrm{m}, P<0.001$ ), however the mean difference was only $13.8 \pm 18.0 \mu \mathrm{m}$. In 223 of 284 eyes $(78.5 \%)$, CCT measurements taken by community optometrists were within $20 \mu \mathrm{m}$ of those obtained in the glaucoma clinic. 61 of 284 (21.5\%) differed by $>20 \mu \mathrm{m}, 40(14.1 \%)$ by $>30 \mu \mathrm{m}$ and $17(6.0 \%)$ by $>50 \mu \mathrm{m}$. There was no significant relationship between difference in CCT and IOP $(-0.02,95 \% \mathrm{CI}-0.05$ to $0.002, P=0.077)$, gender $(0.00,95 \% \mathrm{CI}-0.01$ to $0.01, P=$ $0.805)$, or age $(-0.01,95 \% \mathrm{CI}-0.08$ to $0.06, P=0.791)$.

Conclusions There was good overall agreement between CCT measured by community optometrists and measurements obtained in the glaucoma clinic. The tendency for thicker CCT measurements by community optometrists may be due to more peripheral or non-perpendicular positioning of the pachymeter relative to the cornea.
\end{abstract}

\section{Introduction}

Glaucoma is the second most common cause of blind and partial sight certification in the United Kingdom [1]. It accounts for up to $20 \%$ of referrals to hospital eye services and, with an ageing population, its prevalence is likely to increase. Central corneal thickness (CCT) is an important risk factor for glaucoma which can also confound intraocular pressure (IOP) measurements [2]. Therefore, assessment of CCT is an essential component of the examination

Andrew J Tatham

andrewjtatham@gmail.com

1 Princess Alexandra Eye Pavilion and Department of Ophthalmology, University of Edinburgh, Edinburgh, UK

2 Edinburgh Medical School, The University of Edinburgh, Edinburgh, UK of patients with ocular hypertension (OHT) or suspected glaucoma [3].

Despite the importance of CCT, until recently, few community optometrists have had access to a pachymeter with a survey [4] in 2008 showing only 7\% had the instrument in their practices. In 2015, The Scottish Intercollegiate Guidelines Network (SIGN), published guidelines on referral of patients with glaucoma [5]. The guidelines state that "CCT should be measured in patients with OHT or suspected glaucoma and reported alongside IOP when referring to secondary-eye-care services". The aim was to aid referral refinement and improve risk profiling in the community, reducing unnecessary referral to hospital services of those at low risk.

To enable implementation of the guideline, in March 2016, NHS Education for Scotland provided every community optometric practice in Scotland with a pachymeter and offered training in use of the device [6]. As far as we are aware, Scotland is the first country to have adopted this 
strategy, but no previous studies have investigated agreement between measurements of CCT taken by optometrists in primary care and measurements obtained in glaucoma clinics. The aim of this study was to examine this agreement as, although measurement of CCT is usefully straightforward, inaccuracies could lead to errors in risk stratification and failure to refer an at-risk patient for consultation with a glaucoma specialist.

\section{Methods}

This was a retrospective review of consecutive new patients referred from community optometrists to the glaucoma clinic at Princess Alexandra Eye Pavilion, NHS Lothian, Edinburgh, UK between June 2016 and November 2016. The study methods were approved by the Princess Alexandra Eye Pavilion quality improvement committee and all methods adhered to the tenets of the Declaration of Helsinki. The number of participating optometrists was not known, but all referrals were received from a cohort of 114 optometry practices registered with NHS Lothian, the Scottish Health Board. 769 consecutive new referrals with OHT, suspected glaucoma or glaucoma were identified from the electronic patient administration system. Of these, 54 were excluded: 21 due to a missing referral letter or missing data from the hospital visit and 33 due to failure of the patient to attend their hospital appointment, leaving 715 subjects

Optometrists completed a standard referral letter which requested information including visual acuity, refraction, IOP, optic disc findings, reason for referral, and CCT. CCT was recorded for 142 subjects (19.9\%). The type of pachymeter was not recorded on the referral letter, however, as optometrists had been provided with a standard ultrasound pachymeter (USP), the PachPen (Accutome Inc), and as pachymetry was seldom performed prior to distribution of this device, it is likely that the PachPen was used for most patients. IOP was measured by community optometrists using applanation tonometry in $252(88.7 \%)$ subjects and non-applanation tonometry in $28(9.9 \%)$ subjects. In 4 (1.4\%) subjects, the tonometry device was not specified.

The hospital records were reviewed for all 142 subjects and data regarding CCT measurements from the hospital visit was extracted. CCT was measured in the glaucoma clinic by a trained technician also using the PachPen pachymeter. CCT was measured after instillation of a drop of local anaesthetic (Oxybuprocaine hydrochloride 0.4\%, Bausch \& Lomb Minims, Surrey). The PachPen generates a CCT reading by automatically taking the average of up to 9 measurements. The PachPen is also equipped with digital signal analysis software designed to eliminate nonperpendicular measurements. All subjects also received a comprehensive eye examination in the glaucoma clinic. Tests included slit lamp biomicroscopy, gonioscopy, optic disc and fundus examination and automated visual field testing (SITA fast or SITA standard 24-2 strategy using the Humphrey Field Analyzer, Carl Zeiss Meditec). Patients found to have corneal disease at their hospital visit were excluded. IOP was measured at the glaucoma clinic visit using Goldmann applanation tonometry for all subjects.

\section{Statistical analysis}

Descriptive statistics included mean and standard deviation for normally distributed variables, using the $t$-test used for group comparison for continuous variables and Fisher-exact test for comparison of categorical variables. The difference between CCT measurements was calculated using absolute values and Bland-Altman plots were used to evaluate agreement between CCT measurements obtained by community optometrists and CCT measurements in the glaucoma clinic. All tests were two-sided and a $P$-value $<0.05$ was considered statistically significant. All analyses were performed using Stata Version 13.0 (Stata Corp, College Station, TX).

\section{Results}

Included subjects had an average age of $67.4 \pm 13.4$ years. 81 of $142(57.0 \%)$ were female. Clinical and demographic characteristics shown in Table 1. CCT measured by community optometrists was on average slightly thicker than CCT measured in the glaucoma clinic $(558.3 \pm 41.5 \mu \mathrm{m}$ vs. $552.6 \pm 58.8, P<0.001)$ but the average difference was only $13.8 \pm 18.0 \mu \mathrm{m}$. Figure 1 shows the distribution of differences in CCT. In 223 of 284 eyes (78.5\%), CCT measurements taken by community optometrists were within $20 \mu \mathrm{m}$ of those obtained in the glaucoma clinic. 61 of 284 (21.5\%) measurements differed by $>20 \mu \mathrm{m}, 40$ (14.1\%) by $>30 \mu \mathrm{m}, 26(9.2 \%)$ by $>40 \mu \mathrm{m}$ and $17(6.0 \%)$, by $>50 \mu \mathrm{m}$.

There was a strong relationship between CCT measurements obtained by community optometrists and those from

Table 1 Demographic and clinical characteristics of included subjects

Community Glaucoma clinic $P$-value
optometrist

\begin{tabular}{|c|c|c|c|}
\hline Age (years) & \multicolumn{2}{|c|}{$67.4 \pm 13.4$ (range 19-94) } & NA \\
\hline $\begin{array}{l}\text { Gender } \\
\text { (female) }\end{array}$ & \multicolumn{2}{|l|}{$81(57 \%)$} & NA \\
\hline \multirow{2}{*}{$\begin{array}{l}\text { IOP } \\
(\mathrm{mmHg})\end{array}$} & $19.4 \pm 5.1$ & $18.4 \pm 4.7$ & $<0.001$ \\
\hline & $\begin{array}{l}\text { (88.7\% applanation } \\
\text { tonometry) }\end{array}$ & $\begin{array}{l}\text { (100\% applanation } \\
\text { tonometry) }\end{array}$ & \\
\hline $\mathrm{CCT}(\mu \mathrm{m})$ & $558.3 \pm 41.5$ & $552.6 \pm 58.8$ & $<0.001$ \\
\hline
\end{tabular}




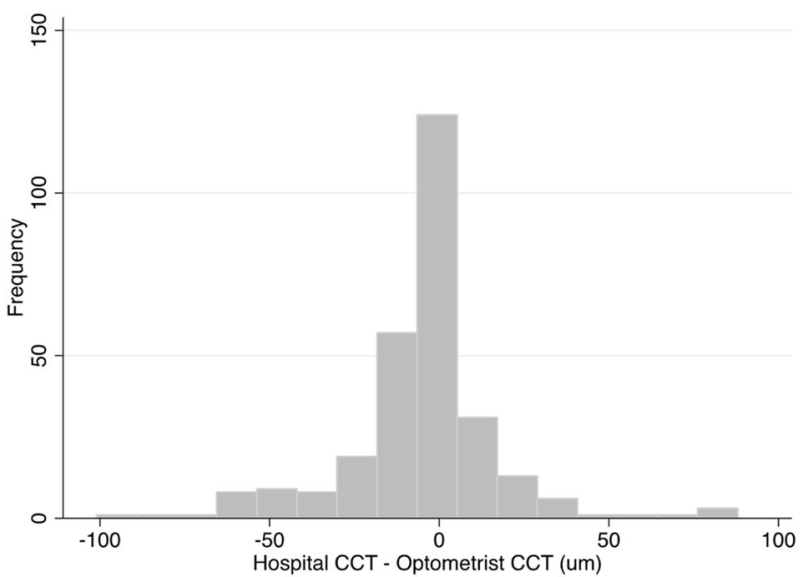

Fig. 1 Histogram showing the distribution of difference between CCT measurements by community optometrists and in the glaucoma clinic

the glaucoma clinic $\left(R^{2}=0.7206\right.$, coefficient $0.793,95 \% \mathrm{CI}$ $0.694-0.893, P<0.001)$. A Bland-Altman plot showing the relationship between the average and difference in CCT obtained by community optometrists and at the hospital visit is shown in Fig. 2. Regression of difference between hospital and community optometrist measured CCT and average CCT showed evidence of proportional bias with a greater difference with increasing average CCT (coefficient $=0.14,95 \%$ CI $0.09-0.190, P<0.001)$. Accounting for proportional bias, the mean difference in CCT measurements was $35.95+(-0.07 \times$ average CCT $)$, with $95 \%$ limits of agreement of $\pm 2.46 \times(-$

$63.72+0.14 \times$ average CCT). Therefore, for a patient with an average CCT measurement of $500 \mu \mathrm{m}$, the expected difference in CCT between community optometrists and the glaucoma clinic was only $0.95 \mu \mathrm{m}(35.95+(-0.07 \times 500))$, compared to a difference of $6.05 \mu \mathrm{m}(35.95+(-0.07 \times 600))$ for patients with an average CCT of $600 \mu \mathrm{m}$. Regression analyses showed no relationship between the difference in CCT measurements and IOP $(-0.02,95 \% \mathrm{CI}-0.05$ to 0.002 , $P=0.077)$, gender $(0.00,95 \% \mathrm{CI}-0.01$ to $0.01, P=0.805)$, or age $(-0.01,95 \% \mathrm{CI}-0.08$ to $0.06, P=0.791)$.

The relationship between IOP measurements by community optometrists and those taken in the glaucoma clinic was also examined (Fig. 3). The mean difference in IOP measurements between visits was $0.75 \pm 0.09 \mathrm{mmHg}$ with $95 \%$ limits of agreement of $\pm 2.46 \mathrm{mmHg}$ [LH1] $(0.47+$ $0.11 \times$ average IOP). There was a significant but weak relationship between thicker CCT and higher IOP (based on hospital measurements: $R^{2}=0.053, P<0.001$ ). Each $10 \mu \mathrm{m}$ thicker CCT was associated with $0.28 \mathrm{mmHg}$ higher IOP (95\% CI $0.14-0.42 \mathrm{mmHg}, P<0.001$ ). The relationship between community optometry measures of CCT and IOP was stronger $\left(R^{2}=0.123, P<0.001\right)$, with each $10 \mu \mathrm{m}$ thicker CCT associated with $0.46 \mathrm{mmHg}$ higher IOP $(95 \%$ CI $0.03-0.06, P<0.001)$.

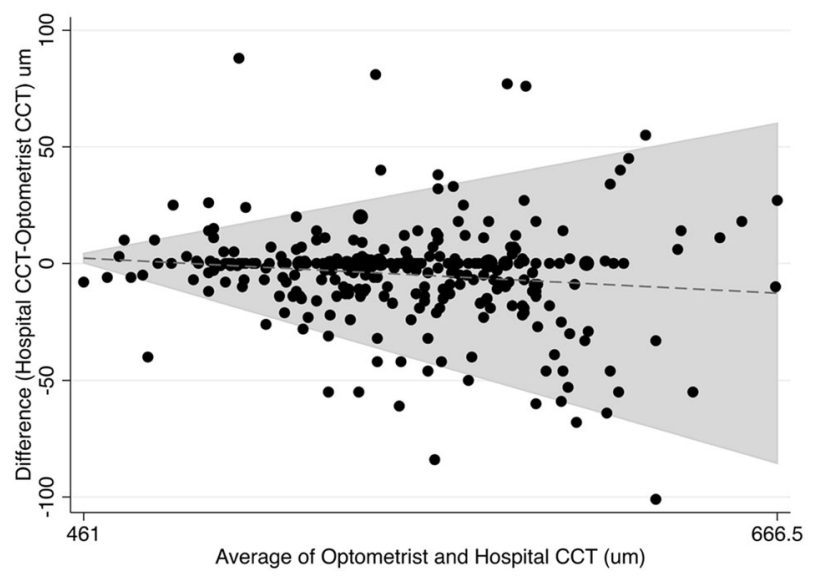

Fig. 2 Bland-Altman plot comparing CCT measurements by community optometrists and in the glaucoma clinic

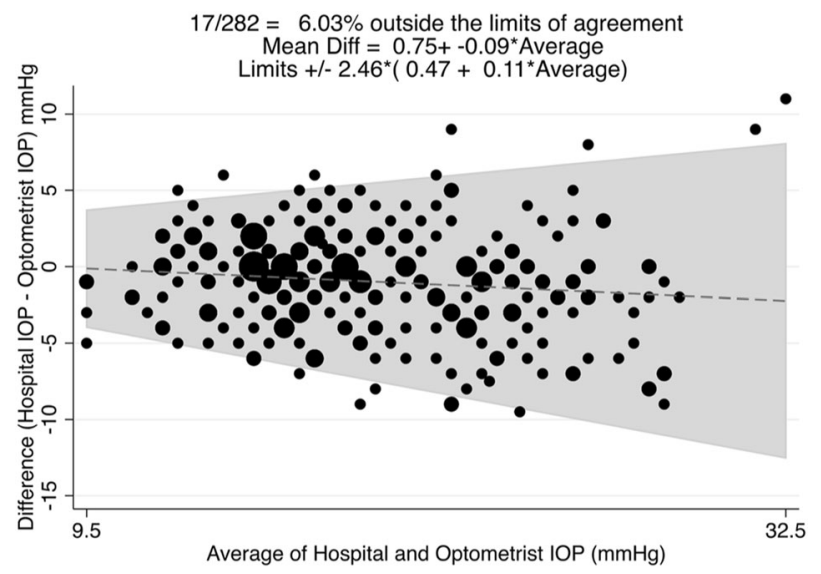

Fig. 3 Bland Altman plot comparing intraocular pressure measurements between community optometrists and the glaucoma clinic

As two eyes of a subject are likely to show correlation, we repeated the analysis using only the right eye of each individual. CCT measured by community optometrists remained significantly thicker $(558.6 \pm 3.5$ vs. $552.9 \pm 3.2 \mu \mathrm{m}, P=$ 0.003 ) for a difference of $14.2 \pm 18.9 \mu \mathrm{m}$. Bland-Altman analysis for right eyes alone, showed a mean difference accounting for proportional bias of $52.19 \pm 0.10 \times$ average CCT and $95 \%$ limits of agreement of $\pm 2.46 \times(-83.19+$ $0.18 \times$ average $\mathrm{CCT}$ ).

\section{Discussion}

The results of this study indicate good overall agreement between CCT measurements obtained by community optometrists and those measured in the glaucoma clinic. On average, CCT measured by optometrists was slightly thicker than that measured in the glaucoma clinic, yet the average difference was only $13.8 \pm 18.0 \mu \mathrm{m}$. Such a small average difference may be of negligible clinical significance. 
However, treatment guidelines- such as those from NICEclassify eyes as having thin, medium or thick corneas ("less than 555 micrometres", "555-590 micrometres" and "more than 590 micrometres") and, therefore, even small differences in CCT may result in a patient falling on a different side of a cut-off value for risk stratification. As an eye with a CCT of $554 \mu \mathrm{m}$ is unlikely to be at significantly greater risk than an eye with a CCT of $556 \mu \mathrm{m}$, it may be better to develop risk prediction tools that allow input of continuous variables.

Despite the overall minimal difference in average CCT, we found a small number of patients with a large difference in CCT measurements at the two visits, with almost $10 \%$ of patients having CCT measurements differing by $>40 \mu \mathrm{m}$. In most of these cases $(77 \%, 20$ of 26), the community optometrist CCT measurement was greater than the hospital CCT measurement. The tendency for CCT measurements by community optometrists to be thicker than measurements in the glaucoma clinic may be due to differences in measurement technique. The centre of the cornea is its thinnest part [7] and therefore CCT measurements taken 'off-axis', in the more peripheral cornea, will result in thicker measurements, as will measurements taken with the pachymeter held at an angle other than directly perpendicular to the corneal surface. It follows that the thinner measurement may then be more likely to represent the true CCT and therefore be the more accurate measurement. Although modern pachymeter digital signal analysis is designed to eliminate non-perpendicular measurements [8], they may not be eliminated entirely. Guidelines [5] for optometrists currently recommend taking "repeat measurements on a single occasion" and documenting "a final reading based on an average of measurements". Yet, using an average of CCT measurements has the possibility of including thicker, off-axis measurements. We would suggest, instead, taking several readings from each eye and using the thinnest measurement may better reflect the true CCT.

Previous studies have shown good intra- and interobserver reproducibility of pachymetry, when employed by well-trained examiners [9-13]. Gunvant et al [14] found a measurement variation of less than $0.2 \%$ in a study in which CCT measurements were taken by two skilled observers of 42 eyes within 5-minute intervals of one another. In a study by Miglior et al. [15], measurements of 51 eyes were taken by 3 well-trained individuals within 3 4 min of each other in order to exclude any possible influence of diurnal variation on CCT. Variations of $\geqslant \pm 15$ $\mu \mathrm{m}$ between two repeated measurements occurred in $11.3 \%$ of test-retest intraobserver evaluations and in $22 \%$ of test-retest interobserver evaluations, demonstrating that even when the same operator performs the CCT examinations, care should be taken in interpretation of the readings. By comparison, we found $28.2 \%$ (80 of 284) measurements differed by $\geqslant \pm 15 \mu \mathrm{m}$, slightly higher than that reported by Miglior et al.

It is important to acknowledge that the current study has several limitations. We did not examine the repeatability of CCT measurements in either the community or hospital setting and as there was no gold standard CCT measurement, it is not possible to determine which measurements were most accurate. An improved methodology would have been to repeat CCT measurements a further time in the glaucoma clinic to allow comparison between repeat hospital measurements and optometrist compared to hospital measurements. In addition, we were not able to determine exactly how many CCT measurements were obtained for each patient in the community and whether the same methodology of averaging up to 9 measurements was followed by community optometrists as in the glaucoma clinic. However, we did not wish to introduce performance bias by informing optometrists we were auditing their CCT measurements and one might expect that the optometrists also followed the manufacturers recommendations. It is also important to acknowledge that the study was conducted shortly after introduction of pachymeters in community optometry and it is possible that agreement may now be better as optometrists develop more experience with pachymetry.

It is also conceivable that the differences in CCT noted may have been due to genuine changes in CCT rather than measurement error. For example, numerous cross-sectional studies have suggested CCT decreases with age [16-23] and changes in corneal hydration might affect measurements. Corneal thickness has also been reported to exhibit diurnal variation [24], with higher thicknesses in the morning due to corneal metabolic change and swelling during sleep [25-27]. Topical glaucoma medication may also affect readings, with timolol reported to increase CCT [28] and latanoprost to decrease $\mathrm{it}^{39}$. However, as the patients included in this study were all new referrals, none were using anti-glaucoma medication [29]. Long term contact lens wear may also decrease CCT [30, 31] and corneal surface irregularity from dry eyes may cause erroneous readings. We did not exclude contact lens wearers, which may have influenced the variation in measurements. Furthermore, we did not analyse correlation between the time of day and CCT measurements. With these omissions, it is then interesting to consider that, in a review and metaanalysis, Doughty et al [32] discusses that diurnal effects, contact lens wear and pharmaceutical use generally produce CCT changes well within the "expected variance" (a coefficient of variation that averaged $5.8 \%$ to the included study mean CCT value of $536 \mu \mathrm{m}$ ) and so may be considered clinically insignificant.

Overall, despite these limitations, the results of this study show good agreement between community optometrist and 
hospital measurement of CCT, indicating that pachymetry can be accurately performed in the community to aid risk profiling of those with OHT and suspected glaucoma. We would suggest the most precise measurement of true CCT is likely to be obtained by taking the thinnest, rather than the average, of multiple measurements.

\section{Summary}

\section{What was known before}

1. Central corneal thickness (CCT) is an important risk factor for glaucoma.

2. CCT also influences intraocular pressure (IOP) measurements.

3. Accurate CCT measurements on referral letters to secondary care can improve triage and onward management of ocular hypertension and glaucoma patients.

4. Optometrists in Scotland are becoming more familiar with pachymetry.

\section{What this study adds}

1. No previous studies have investigated agreement between measurements of CCT taken by optometrists in primary care and measurements obtained in glaucoma clinics.

2. Our study aimed to examine this agreement as, although measurement of CCT is usefully straightforward, inaccuracies could lead to errors in risk stratification and failure to refer an at-risk patient for consultation with a glaucoma specialist.

3. Our study showed an excellent agreement between CCT measured by community optometrists and measurements obtained in the glaucoma clinic.

4. We make suggestions for pachymetry technique to aid accuracy in referrals and improve patient riskprofiling.

Acknowledgements We thank Dr Nikki Hall, University of Edinburgh, for her assistance in converting image files to appropriate formats for submission.

\section{Compliance with ethical standards}

Conflict of interest The authors declare that they have no conflict of interest.

\section{References}

1. Bunce C, Xing W, Wormald R. Causes of blind and partial sight certifications in England and Wales: April 2007-March 2008. Eye (Lond). 2010;24:1692-9.
2. Gordon MO, Beiser JA, Brandt JD, Heuer DK, Higginbotham EJ, Johnson CA, et al. The ocular hypertension treatment study baseline factors that predict the onset of primary open-angle glaucoma. Arch Ophthalmol. 2002;120:714-720. for the Ocular Hypertension Treatment Study Group

3. National Collaborating Centre for Acute Care. NICE guidelines CG85 glaucoma: diagnosis and management of chronic open angle glaucoma and ocular hypertension. 2009. http://www.nw lloc.com/guidelines/CG85NICEGuideline.pdf.

4. Myint J, Edgar DF, Kotecha A, Murdoch IE, Lawrenson JG. A national survey of diagnostic tests reported by UK community optometrists for the detection of chronic open angle glaucoma. Ophthalmic Physiol Opt. 2011;31:353-359.

5. Scottish Intercollegiate Guidelines Network. Glaucoma referral and safe discharge. A national clinical guideline. Edinburgh: SIGN; 2015 (SIGN Guideline no. 144). 2015. http://www.sign.ac. uk/guidelines/fulltext/144/index.html.

6. Goudie C, Pronin S, Court H, Pooley J, Tatham AJ. A national survey of the use of pachymeters by optometrists in Scotland: experience, views and barriers to use. Ophthalmic Physiol Opt. 2017;37:177-183.

7. Liu Z, Huang A, Pflugfelder S. Evaluation of corneal thickness and topography in normal eyes using the Orbscan corneal topography system. Br J Ophthalmol. 1999;83:774-778.

8. Keeler, Accutome PachPen Handheld Pachymeter [Online]. http://accutome.com/pachpen-handheld-pachymeters, 25 August 2017.

9. Muscat S, McKay N, Parks S, Kemp E, Keating D. Repeatability and reproducibility of corneal thickness measurements by optical coherence tomography. Invest Ophthalmol Vis Sci. 2002;43:1791-1795.

10. Karadag R, Unluzeybek M, Cakici O, Kanra AY, Bayramlar H. Reproducibility and repeatability of central corneal thickness measurement in healthy eyes using four different optical devices. Int Ophthalmol. 2017;37:1039-1045.

11. Marsich MW, Bullimore MA. The repeatability of corneal thickness measures. Cornea. 2000;19:792-795.

12. Kiddee $\mathrm{W}$, Horattanareung $\mathrm{O}$. Intraoperator repeatability and interoperator reproducibility in the ultrasonic pachymetry measurements of central corneal thickness. J Med Assoc Thai. 2009;92:672-676.

13. Gordon A, Boggess EA, Molinari JF. Variability of ultrasonic pachometry. Optom Vis Sci. 1990;67:162-165.

14. Gunvant P, Broadway DC, Watkins RJ. Repeatability and reproducibility of the BVI ultrasonic Pachymeter. Eye (Lond). 2003; 17:825-828.

15. Miglior S, Albe E, Guareschi M, Mandelli G, Gomarasca S, Orzalesi N. Intraobserver and interobserver reproducibility in the evaluation of ultrasonic pachymetry measurements of central corneal thickness. Br J Ophthalmol. 2004;88:174-177.

16. Hashmani N, Hashmani S, Hanfi AN, Ayub M, Saad CM, Rajani $\mathrm{H}$, et al. Effect of age, sex, and refractive errors on central corneal thickness measured by Oculus Pentacam ${ }^{\circledR}$. Clin Ophthalmol. 2017;11:1233-1238.

17. Hahn S,Azen S,Ying-Lai M,Varma R. The Los Angeles Latino Eye Study Group Central Corneal Thickness in Latinos. Invest Ophthalmol Vis Sci. 2003;44:1508-1512.

18. Godar ST, Kaini KR, Khattri JB. Factors affecting the central corneal thickness in Nepalese population. Nepal J Med Sci. 2012;1:7-10.

19. Cho P, Lam C. Factors affecting the central corneal thickness of Hong Kong-Chinese. Curr Eye Res. 1999;18:368-374.

20. Gelaw Y. The impact of central corneal thickness on intraocular pressure among Ethiopian glaucoma patients: a cross-sectional study. BMC Ophthalmol. 2012;12:58. 
21. Galgauskas S, Juodkaite G, Takamine J. Age-related changes in central corneal thickness in normal eyes among the adult Lithuanian population. Clin Interv Aging. 2014;9:1145-1151.

22. Galgauskas S, Norvydaite D, Krasauskaitè D, Stech S, Ašoklis RS. Age-related changes in corneal thickness and endothelial characteristics. Clin Interv Aging. 2013;8:1445-1450.

23. Iyamu E, Osuobeni E. Age, gender, corneal diameter, corneal curvature and central corneal thickness in Nigerians with normal intra ocular pressure. J Optom. 2012;5:87-97.

24. Feng Y, Varikooty J, Simpson TL. Diurnal variation of corneal and corneal epithelial thickness measured using optical coherence tomography. Cornea. 2001;20:480-3.

25. Lattimore MR Jr, Kaupp S, Schallhorn S, Lewis R 4th. Orbscan pachymetry: implications of a repeated measures and diurnal variation analysis. Ophthalmology. 1999;106:977-81.

26. Fogagnolo P, Rossetti L, Mazzolani F, Orzalesi N. Circadian variations in central corneal thickness and intraocular pressure in patients with glaucoma. Br J Ophthalmol. 2006; 90:24-28.
27. Klyce SD. Stromal lactate accumulation can account for corneal oedema osmotically following epithelial hypoxia in the rabbit. J Physiol. 1981;321:49-64.

28. Nielsen CB, Nielsen PJ. Effect of alpha- and beta-receptor active drugs on corneal thickness. Acta Ophthalmol (Copenh). 1985;63:351-4.

29. Lass JH, Eriksson GL, Osterling L, Simpson CV, Latanoprost Corneal Effects Study Group. Comparison of the corneal effects of latanoprost, fixed combination latanoprost-timolol, and timolol: a double-masked, randomized, one-year study. Ophthalmology. 2001;108:264-71. Latanoprost Corneal Effects Study Group

30. Braun D, Penno E. Effect of contact lens wear on central corneal thickness measurements. J Cataract Refract Surg. 2003;29: $1319-1322$

31. Liu Z, Pflugfelder SC. The effects of long-term contact lens wear on corneal thickness, curvature, and surface regularity. Ophthalmology. 2000;107:105-111.

32. Doughty MJ, Zaman ML. Human corneal thickness and its impact on intraocular pressure measures. A review and meta-analysis approach. Surv Ophthalmol. 2000;44:367-408. 